\title{
SMALL MOLECULAR IONS AS IMPURITY CENTRES IN CRYSTALS
}

\author{
K. K. Rebane and L. A. Rebane \\ Institute of Physics and Astronomy, Academy of Sciences of the Estonian SSR, \\ 202400 Tartu, USSR
}

\begin{abstract}
The present status and results of the spectroscopic study of molecular ions, inserted into alkali halide crystals, are reviewed.

The vibronic spectra of a number of molecular centres $\left(\mathrm{O}_{2}^{-}, \mathrm{S}_{2}^{-}, \mathrm{NO}_{2}^{-}\right.$, $\mathrm{PO}_{2}^{-}$) contain clear-cut series of zero-phonon lines. For these centres the data about the parameters of intramolecular vibrations, anharmonic constants and adiabatic potentials are discussed. The librational-rotational motion of impurity molecules is revealed in the spectra of infrared absorption, vibronic absorption, luminescence and Raman scattering. Molecular centres are also perspective objects for the spectroscopic study of the local lattice dynamics and anharmonic effects. In the case of the $\mathrm{NO}_{2}^{-}$centres the data on the hot luminescence spectrum and characteristic relaxation times are considered.
\end{abstract}

\section{INTRODUCTION}

Small negative molecular ions, inserted in an ionic crystal matrix, are of interest at least from two aspects.

Firstly, an ionic crystal is a stabilizing medium for negative molecular ions. Thus, free ions $\mathrm{O}_{2}^{-}, \mathrm{S}_{2}^{-}$and $\mathrm{NO}_{2}^{-}$and others are not stable and the knowledge of their properties is very poor. The same molecular ions, inserted into an ionic crystal as impurities, become stable both in the ground and excited electronic states. On the other hand, a number of molecular ions, isolated in the crystal matrix, retain their basic characteristics--electronic structure, intramolecular vibrations and to some extent even rotationwithout radical changes. This means that the investigation of molecular centres in ionic crystals is close to the matrix isolation spectroscopy of molecules.

Secondly, the above-mentioned molecular ions form molecular luminescence centres in crystals. This enables them to be used as luminescence probes for the study of crystal properties and the interaction of impurities with crystals.

Most of the studies carried out up to now are connected with molecules inserted in alkali halide crystals. We will restrict ourselves to these hosts and will mainly consider the molecular ions $\mathrm{O}_{2}^{-}, \mathrm{S}_{2}^{-}, \mathrm{NO}_{2}^{-}$and also $\mathrm{PO}_{2}^{-}$, $\mathrm{OH}^{-}$and $\mathrm{SH}^{-}$. 
Various spectroscopic and luminescence methods have been applied: low-temperature spectra of vibronic absorption and luminescence, spectra of resonant and non-resonant Raman scattering of light (r.s.), infrared absorption (i.r.), excitation of luminescence, hot luminescence (h.l.), and also the dependence of the quantum yield of luminescence on the excitation frequency and temperature being studied. A number of valuable results about the structure of the impurity centres $\mathrm{O}_{2}^{-}, \mathrm{S}_{2}^{-}, \mathrm{Se}_{2}^{-}$with a free spin have been obtained by e.s.r. methods.

The systems under study have also been widely used in investigations of paraelectrical cooling ${ }^{1-7}$, and low-temperature thermal capacity and thermal conductivity of crystals ${ }^{8-10}$.

It is well known that in alkali halide crystals the electron-phonon interaction is strong. As a result of this the absorption and luminescence spectra of a number of impurity luminescence centres consist of broad bell-shaped bands containing rather little spectroscopic information (the spectrum of the $\mathrm{Tl}^{+}$ion in the crystal serves as a typical example here).

In the case of molecular ionic centres of luminescence the situation is entirely different. The spectrum has a clear-cut vibronic structure owing to the excitation of intramolecular (local mode) vibrations in the electronic transition. For such a molecule in a crystal the main outlines of the structure of the vibronic spectrum are in general the same as those of a free simple molecule: there are series of rather broad lines (sub-bands) whose intensities are determined by Franck-Condon factors. A more detailed investigation shows the existence of a further structure of sub-bands, very characteristic of impurity centres in crystals: the zero-phonon lines and phonon wings appear in vibronic sub-bands at low temperatures. The latter have in their turn a fine structure. The observed line widths are about $1 \mathrm{~cm}^{-1}$ and this enables the series of isotopic lines ${ }^{11,12}$, a fine rotational splitting of zerophonon lines ${ }^{13,14}$, and structural details of the phonon sidebands ${ }^{15-19}$ to be detected. and also (in the case of $\mathrm{NO}_{2}^{-}$) a reliable interpretation of hot luminescence spectra to be given ${ }^{20}$.

The large amount of information contained in the spectra of molecular impurities has a simple explanation: a molecule carries high-frequency intramolecular vibrations with it into the crystal, and these act as highfrequency local vibrations in a system of normal vibrations of the activated crystal.

Appreciable Stokes losses on a local vibration give rise to the extended series of vibronic sub-bands. Owing to the high frequency of local vibrations $\left(\sim 1000 \mathrm{~cm}^{-1}\right.$ for $\mathrm{O}_{2}^{-}$, i.e. $4-5$ times higher than the maximum frequency of the host lattice vibrations), single vibronic bands can be easily distinguished.

The interaction with crystal vibrations is essentially weaker it has, as one should expect, a considerable dependence on the host crystal. As a whole, however, it remains weak or moderate and this guarantees a distinct separation of a narrow zero-phonon line and a phonon sideband in every vibronic sub-band at low temperatures. As a result, the fine structure of vibronic sub-bands is repeated a number of times in the series due to intramolecular modes. Let us note that this is an additional useful circumstance which makes it possible to obtain some more valuable information and to interpret the details of the spectral structure much more reliably. 
It should be mentioned that the vibronic structure of the spectra of molecular centres may serve as an excellent illustration of the theoretical picture of the impurity spectrum in the case of a strong interaction of the electronic transition with the high-frequency local mode in the centre, and a weak or medium interaction with the phonons of crystal vibrations ${ }^{21}$.

The easily observed and interpreted structure of low-temperature luminescence and absorption spectra has attracted considerable attention of a number of authors ${ }^{11-19,22,23}$. A summary of these studies up to 1970 has been made by one of $\mathrm{us}^{24}$.

In the present paper we will mainly consider the new results in this field, which have been obtained from vibronic spectra, Raman scattering, and infrared absorption and hot luminescence spectra.

\section{THE STRUCTURE OF MOLECULAR IMPURITY CENTRES IN ALKALI HALIDE CRYSTALS}

Small molecular ions $\left(\mathrm{O}_{2}^{-}, \mathrm{OH}^{-}, \mathrm{SH}^{-}, \mathrm{CN}^{-}, \mathrm{NO}_{2}^{-}\right.$, etc.) are easily introduced into the lattice of alkali halide crystals, by doping the melts with small doses of corresponding salts of alkali metals. In most cases the impurity molecule replaces the halide anion in the lattice. The symmetry of the molecular centre is determined. besides the symmetry of the molecule and the host crystal. also by the orientation of the molecular axis relative to the crystal axes (see Table 1).

Table 1. Symmetry of molecular centres in cases of different orientations of the main axis of the molecule in a cubic crystal. The molecular centre of mass is considered to coincide with the site of the lattice

\begin{tabular}{lllll}
\hline Free molecule & $\begin{array}{c}\text { Molecular } \\
\text { symmetry group }\end{array}$ & \multicolumn{2}{c}{$\begin{array}{c}\text { Crystal axis coinciding with the } \\
\text { main molecular axis }\end{array}$} \\
\hline $\mathrm{O}_{2}^{-}, \mathrm{S}_{2}^{-}$ & $C_{4}$ & $C_{3}$ & $C_{2}$ \\
$\mathrm{CN}^{-}, \mathrm{OH}^{-}, \mathrm{SH}^{-}$ & $D_{\infty \mathrm{h}}$ & $D_{4 \mathrm{~h}}$ & $D_{3 \mathrm{~d}}$ & $D_{2 \mathrm{~h}}$ \\
$\mathrm{NCO}^{-}, \mathrm{NCS}^{-}$ & $C_{\infty \mathrm{v}}$ & $C_{4 \mathrm{v}}$ & $C_{3 \mathrm{v}}$ & $C_{2 \mathrm{v}}$ \\
$\mathrm{NO}_{2}^{-}$ & $C_{\infty \mathrm{v}}$ & $C_{4 \mathrm{v}}$ & $C_{3 \mathrm{v}}$ & $C_{2 \mathrm{v}}$ \\
$\mathrm{NO}_{3}^{-}$ & $C_{3 \mathrm{v}}^{2 \mathrm{v}}$ & $C_{2 \mathrm{v}}$ & $C_{\mathrm{s}}$ & $C_{2 \mathrm{v}}$ \\
\hline
\end{tabular}

* This symmetry corresponds to specific symmetrical orientations of the $C_{2}$ axis of the molecule.

Spin resonance studies of $\mathrm{O}_{2}^{-}$and $\mathrm{S}_{2}^{-}$centres gave the equilibrium orientation of molecular axes along $\langle 110\rangle$. This leads to the orthorhombic symmetry $D_{2 \mathrm{~h}}$ of the centre 25,26 . However, it is possible that in some hosts the orientation of the $\mathrm{O}_{2}^{-}$and $\mathrm{S}_{2}^{-}$molecules is different ${ }^{27,28}$. The question about the structure of these centres will be discussed in more detail below in connection with electron states (Section 3.1) and reorientation processes (Section 4.2). 


\section{K. K. REBANE AND L. A. REBANE}

At high concentrations the pair centres of $\mathrm{O}_{2}^{-}$which are investigated by spin resonance 29.30 begin to form.

The orientation of the $\mathrm{OH}^{-}$ion along $\langle 100\rangle$ directions was found from the electric field induced dichroism of the ultraviolet absorption band ${ }^{31-33}$. The $\langle 100\rangle$ orientation of the $\mathrm{CN}^{-}$ion was found from the dichroism of the i.r. absorption, brought out by the uniaxial stress of the crystals ${ }^{34}$

$\mathrm{NO}_{2}^{-}$ions in $\mathrm{KCl}, \mathrm{KBr}$ and $\mathrm{RbCl}$ crystals undergo a slightly hindered rotation with the potential minima corresponding to the $\langle 110\rangle$ orientation of the molecular axis ${ }^{13,35}$.

The orientation of $\mathrm{NO}_{3}^{-}$ions is discussed on the basis of the results of i.r. absorption spectra. The $C_{3 \mathrm{v}}$ symmetry of the centre, corresponding to the $\langle 111\rangle$ orientation, is most probable ${ }^{36,37}$. However, the $\mathrm{NO}_{2}^{-}$centres in the alkali halides with the $\mathrm{NaCl}$-type lattice and those in crystals with the $\mathrm{CsCl}$ type lattice have been ascribed to $D_{3 \mathrm{~h}}$ and $C_{2 \mathrm{v}}$ symmetry, respectively ${ }^{38.39}$.

The ions carrying two extra electrons $\left(\mathrm{SO}_{4}^{2-}, \mathrm{CrO}_{4}^{2-}\right.$, etc.) form more complicated centres, which trap an anion vacancy or cation impurity to compensate the extra charge ${ }^{40-43}$.

\section{ELECTRON STATES OF MOLECULAR IONS; PARAMETERS OF POTENTIAL CURVES}

\section{1. $\mathrm{O}_{2}^{-}$and $\mathrm{S}_{2}^{-}$}

During the last few years attention has been paid to the determination of the electronic states of $\mathrm{O}_{2}^{-}$which play an important role in the upper layers of the atmosphere. The possible system of its electronic terms is rather complicated. There are 24 lowest electronic states which correspond to the dissociation of the molecules into an $\mathrm{O}$ atom in the ${ }^{3} \mathrm{P}$ state and an $\mathrm{O}^{-}$ion in the ${ }^{2} \mathrm{P}$ state. The electronic configuration of $\mathrm{O}_{2}^{-}$in the ground electronic state is $\left(2 \mathrm{p} \pi_{\mathrm{u}}\right)^{4}\left(2 \mathrm{p} \sigma_{\mathrm{g}}\right)^{2}\left(2 \mathrm{p} \pi_{\mathrm{g}}\right)^{3}$ which gives a twofold degenerate term ${ }^{2} \Pi_{\mathrm{g}}$. The lowest excited states may be the following: ${ }^{2} \Pi_{\mathrm{u}}\left(\pi_{\mathrm{u}}^{3} \sigma_{\mathrm{g}}^{2} \pi_{\mathrm{g}}^{4}\right),{ }^{2} \Sigma_{\mathrm{u}}^{+},{ }^{2} \Sigma_{\mathrm{u}}^{-},{ }^{2} \Delta_{\mathrm{u}}^{\mathrm{g}}$, ${ }^{4} \Sigma_{u}^{-}\left(\sigma_{g}^{2} \pi_{u}^{4} \pi_{g}^{2} \sigma_{u}\right)$, etc. ${ }^{44}$.

Difficulties connected with obtaining the free $\mathrm{O}_{2}^{-}$ion and its low stability $\left(\sim 10^{-10} \mathrm{~s}^{45}\right)$ have led to the situation where reliable values of ionization energy $\left(4.083 \mathrm{eV}^{46}\right)$ and electron affinity $\left(0.40 \mathrm{eV}^{47}\right)$ have only recently been obtained. Attempts have been made to obtain $\mathrm{O}_{2}^{-}$in the argon matrix with the addition of alkali metal atoms, i.e. the impurities tending to lose an electron ${ }^{48}$. However, an $\mathrm{O}_{2}^{-}$ion and its electron analogues $\mathrm{S}_{2}^{-}$and $\mathrm{Se}_{2}^{-}$are easily substituted in alkali halide crystals where they form molecular luminescence centres, i.e. they also have well-localized lowest excited electronic states.

Figure 1 shows the typical low-temperature luminescence and excitation spectra of molecular ions exemplified by the $\mathrm{S}_{2}^{-}$centre in KI. The narrow zero-phonon lines in luminescence enable the energies of vibronic transitions to be determined with high accuracy $\left(\sim 1 \mathrm{~cm}^{-1}\right)$ and the frequencies and anharmonic constants of the intramolecular vibration (Table 2 and Refs. $24,27,49)$ to be obtained. The same data, but with considerably lower accuracy, have been obtained from absorption and excitation spectra (see Figure $1 b$ ), about the lowest excited electronic state of centres ${ }^{50,51}$.

In Figure 2 the adiabatic potentials of the lowest electronic states of the 
(A)
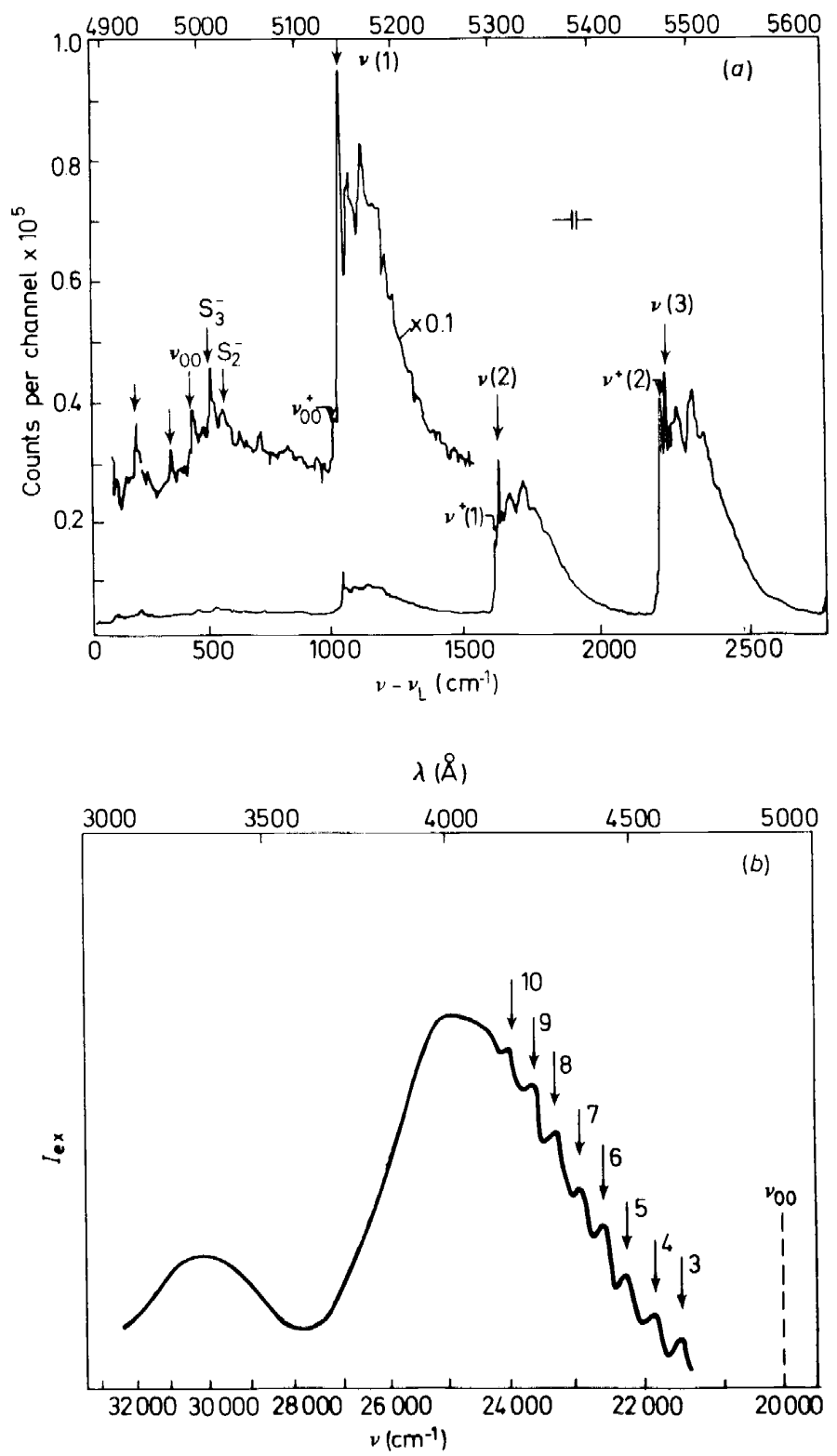

Figure 1, Luminescence $(a)$ and excitation $(b)$ spectra of $\mathrm{S}_{2}^{-}$centres in KI. The KI crystal was heated in sulphur vapours for $150 \mathrm{~h}$.

(a) The luminescence spectrum in the vicinity of the pure electronic line $v_{00}$; excitation with the $4880 \AA$ argon laser line; temperature about $10 \mathrm{~K}$. Superscript + indicates the lines of additional vibronic series; the Raman lines of $S_{2}^{-}$and $S_{3}^{-}$centres are also visible in the phonon sideband of the $v_{00}$ line.

(b) The excitation spectrum of luminescence of $\mathrm{S}_{2}^{-}$at $4.2 \mathrm{~K}$. 
K. K. REBANE AND L. A. REBANE

Table 2. Spectroscopic constants of $\mathrm{O}_{2}^{-}$and $\mathrm{S}_{2}^{-}$impurity ions in the ground electronic state

\begin{tabular}{clccc}
\hline Centre & Crystal & $v_{00}\left(\mathrm{~cm}^{-1}\right)$ & $v_{0}\left(\mathrm{~cm}^{-1}\right)$ & $v_{0} x_{0}\left(\mathrm{~cm}^{-1}\right)$ \\
\hline $\mathrm{O}_{2}^{-}$ & $\mathrm{NaCl}$ & 27283 & 1149 & 8.4 \\
& $\mathrm{NaBr}$ & 26672 & 1139 & 7.9 \\
& $\mathrm{KCl}$ & 27559 & 1153 & 8.3 \\
& $\mathrm{KBr}$ & 26979 & 1141 & 9.0 \\
& $\mathrm{KI}$ & 26514 & 1124 & 8.8 \\
& $\mathrm{RbCl}$ & 27483 & 1150 & 8.5 \\
& $\mathrm{RbBr}$ & 27150 & 1140 & 8.2 \\
& $\mathrm{RbI}{ }^{*}$ & 26761 & 1127 & 8.7 \\
& $\mathrm{CsCl}$ & 26527 & 1136 & 9.1 \\
$\mathrm{~S}_{2}^{-}$ & $\mathrm{CsBr}$ & 26130 & 1120 & 9.0 \\
& $\mathrm{KCl}$ & 20970 & 627.5 & 2.5 \\
& $\mathrm{KBr}$ & 20578 & 616 & 2.2 \\
& $\mathrm{KI}$ & 20026 & 598.6 & 3.0 \\
& $\mathrm{KI}{ }^{*}{ }^{*}$ & 19452 & 598 & 4.5 \\
& $\mathrm{RbBr}$ & 20609 & 614.5 & 2.5 \\
\hline
\end{tabular}

* Data taken from Ref. 27.

$\mathrm{O}_{2}^{-}$ion in the $\mathrm{KBr}$ crystal (curves $\mathrm{U}_{\mathrm{g}}$ and $\mathrm{U}_{\mathrm{u}}$ ) are plotted from the data of the vibronic structure in luminescence and excitation spectra. The adiabatic potential for a free $\mathrm{O}_{2}^{-}$in its ground state was obtained ${ }^{46,52}$ from the energy dependence measurements of the effective cross-section of scattering of slow electrons by the $\mathrm{O}_{2}$ molecule. The potential curve obtained is rather close to the one for the impurity molecule. The potential curves of the excited electronic states of a free $\mathrm{O}_{2}^{-}$ion (dashed lines in Figure 2) are the results of theoretical calculations ${ }^{53}$. It is interesting that the calculated potential of state ${ }^{2} \Pi_{u}$ turns out to be very close to potential $U_{u}$ of the excited electronic state of the $\mathrm{O}_{2}^{-}$centre in $\mathrm{KBr}$. This fact may be considered as a confirmation of the interpretation of the spectrum in a crystal as being due to the molecular transition ${ }^{2} \Pi_{u} \leftrightarrow{ }^{2} \Pi_{g}$.

Spectroscopic studies of the excited electronic states of $\mathrm{O}_{2}^{-}$(as well as $\mathrm{S}_{2}^{-}$and $\mathrm{Se}_{2}^{-}$) are so far possible only on the basis of the spectra of these ions in crystals. The spectra of these impurity centres are very similar: their specific feature is the absence of a clear vibronic structure in the absorption and excitation spectra (see the excitation spectrum for $\mathrm{S}_{2}^{-}$in $\mathrm{KI}$ in Figure $1 b$ ). This is observed only on the long-wave side of the excitation band ${ }^{11,50,51}$. Near the maximum the band is evidently non-elementary. This is in good agreement with the theoretical results ${ }^{53}$ where the existence of some partly overlapping electronic states was obtained. The other band is related to the transition ${ }^{2} \Delta_{\mathrm{u}} \leftarrow{ }^{2} \Pi_{\mathrm{g}}{ }^{26}$.

Comparing the parameters of the molecular centre with those of the free ion it is necessary to take into account the influence of the local field of the crystal matrix, first of all, on the symmetry of the centre. The $\mathrm{O}_{2}^{-}$and $\mathrm{S}_{25}^{-}$ ions form centres with orthorhombic $\left(D_{2 h}\right)$ symmetry in alkali halides $25,26,54,55$. The two orientations of $\pi$ orbitals in the crystal have different energies, i.e. level ${ }^{2} \Pi_{\mathrm{g}}$ is split into ${ }^{2} \Pi_{\mathrm{g}}^{x}$ and ${ }^{2} \Pi_{\mathrm{g}}^{\mathrm{y}}$. It was also shown that for $\mathrm{O}_{2}^{-}$in the potassium and rubidium halides and for $\mathrm{S}_{2}^{-}$in $\mathrm{KCl}$ and $\mathrm{RbBr}$ the ${ }^{2} \prod_{\mathrm{g}}^{x}$ state is the 


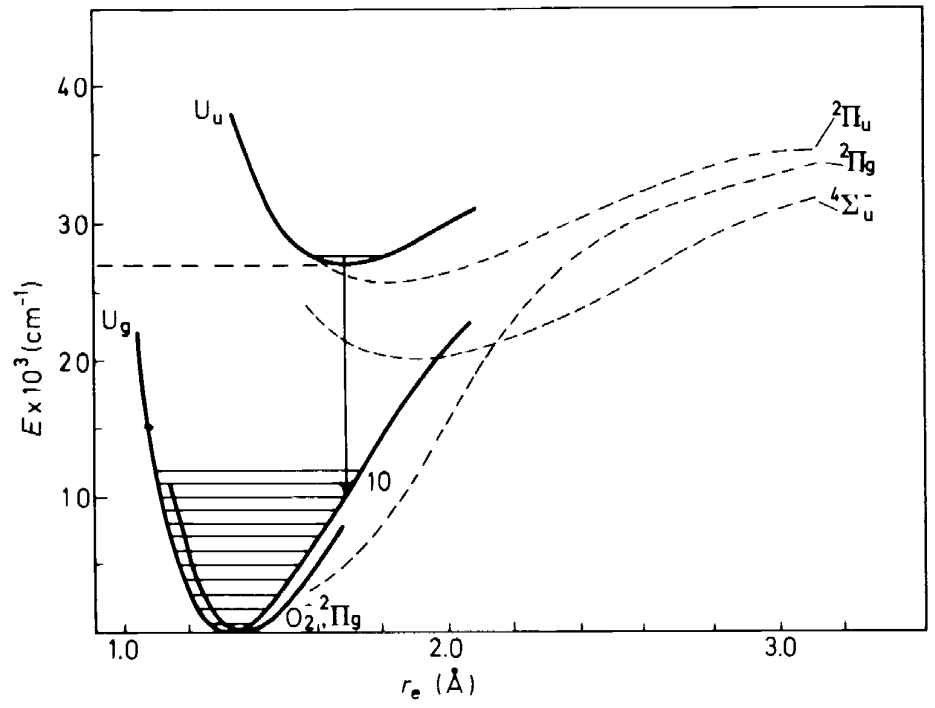

Figure 2. Adiabatic potentials of electronic states of the $\mathrm{O}_{2}^{-}$ion. Curves $\mathrm{U}_{\mathrm{a}}$ and $\mathrm{U}_{4}$ are plotted using the data ${ }^{18,51}$ about the vibronic spectra of $\mathrm{O}_{2}^{-}$in $\mathrm{KBr}$. Curves ${ }^{2} \mathrm{\Pi}_{\mathrm{g}},{ }^{4} \Sigma_{\mathrm{u}}^{-}$and ${ }^{4} \mathrm{\Pi}_{\mathrm{u}}$ (dashed lines) are the result of theoretical calculations ${ }^{53}$. Curve $\mathrm{O}_{2}^{-2} \Pi_{\mathrm{q}}$ was found from electron scattering experiments. ${ }^{52}$

lowest. while for $\mathrm{O}_{2}^{-}$in $\mathrm{NaCl}$ and $\mathrm{NaBr}$ and for $\mathrm{S}_{2}^{-}$in $\mathrm{KBr}$ and $\mathrm{Kl}$ the ${ }^{2} \Pi_{\mathrm{g}}^{y}$ state is the lowest. In accordance with this, additional series of zerophonon lines in the luminescence spectra of $\mathrm{O}_{2}^{-}$and $\mathrm{S}_{3}^{-}$were observed in a number of crystals and ascribed to the splitting of the ${ }^{2} \Pi_{\mathrm{g}}$ state $^{17,19}$. (Such additional series may be clearly seen in the spectra of $\mathrm{S}_{2}^{-}$in KI, Figure 1a.) However, the measurements of the splittings and polarization of zero-phonon lines in the luminescence spectra under uniaxial mechanical stress ${ }^{27}$ led the authors to the conclusion that $\mathrm{O}_{2}^{-}$forms centres with trigonal symmetry $D_{3 \mathrm{~d}}$ in $\mathrm{NaCl}, \mathrm{KBr}$ and $\mathrm{KI}$. In this case the ground electronic state of the centre must remain double degenerate.

\section{2. $\mathrm{NO}_{2}^{-}$and $\mathrm{PO}_{2}^{-}$}

The absorption and luminescence spectra of alkali halide crystals, containing $\mathrm{NO}_{2}^{-}$ions or its isoelectronic analogue. $\mathrm{PO}_{2}^{-}$ions, have at helium temperature a vibronic structure of bands which arises as a result of the excitation of totally symmetric $v_{1}$ and $v_{2}$ intramolecular vibrations ${ }^{13.23 .35}$. 56-58. The frequencies and anharmonic constants of the vibrations of $\mathrm{NO}_{2}^{-}$and $\mathrm{PO}_{2}^{-}$ions, determined on the basis of the spectral data, are presented in Table 3. Because of the narrow zero-phonon lines, especially in the case of $\mathrm{NO}_{2}^{-}$, these values may be given with a rather high accuracy.

The $\mathrm{NO}_{2}^{-}$absorption and luminescence spectra belong to the allowed dipole transition ${ }^{1} \mathrm{~B}_{2} \leftrightarrow{ }^{1} \mathrm{~A}_{1}$. In the case of $\mathrm{PO}_{2}^{-}$, luminescence is due to the triplet-singlet transition ${ }^{3} \mathrm{~B}_{2} \leftrightarrow{ }^{1} \mathrm{~A}_{1}$. The luminescence may be excited 
in the absorption band corresponding to the allowed transition ${ }^{1} \mathrm{~B}_{2} \leftarrow{ }^{1} \mathrm{~A}_{1}$. A very weak luminescence was also obtained at the direct excitation into the triplet state. It is interesting that the corresponding triplet-singlet transition has not been detected in the case of the impurity $\mathrm{NO}_{2}^{-}$centre, but was observed in some nitrite crystals ${ }^{59}$.

Table 3. Spectroscopic constants of $\mathrm{NO}_{2}^{-}$and $\mathrm{PO}_{2}^{-}$impurity ions in the ground and lower excited electronic states; the values are given in $\mathrm{cm}^{-1}$

\begin{tabular}{|c|c|c|c|c|c|c|c|c|c|c|c|}
\hline \multirow{2}{*}{ Centre } & \multirow{2}{*}{ Crystal } & \multicolumn{2}{|c|}{${ }^{1} A_{1}$} & \multirow[b]{2}{*}{$x_{12}$} & \multirow[b]{2}{*}{$x_{22}$} & \multirow[b]{2}{*}{$v_{00}$} & \multirow[b]{2}{*}{$v_{1}^{0}$} & \multicolumn{2}{|l|}{${ }^{1} \mathbf{B}_{2}$} & \multirow[b]{2}{*}{$x_{12}$} & \multirow[b]{2}{*}{$x_{22}$} \\
\hline & & $r_{1}^{\prime \prime}$ & $v_{2}^{0}$ & & & & & $v_{2}^{0}$ & $x_{11}$ & & \\
\hline $\mathrm{NO}_{2}$ & $\begin{array}{l}\mathrm{KCl} \\
\mathrm{KBr} \\
\mathrm{KI} \\
\mathrm{RbCl}\end{array}$ & $\begin{array}{l}1326 \\
\overline{1310}\end{array}$ & $\begin{array}{l}803.4 \\
799 \\
804 \\
801\end{array}$ & $\begin{array}{l}-6.4 \\
- \\
-\end{array}$ & $\begin{array}{l}-0.9 \\
-1.0 \\
-0.5\end{array}$ & $\begin{array}{l}25036.8 \\
24931 \\
24932 \\
24952\end{array}$ & $\begin{array}{c}1003 \\
989.5 \\
987.5 \\
1002\end{array}$ & $\begin{array}{l}599.5 \\
596.8 \\
604 \\
597.5\end{array}$ & $\begin{array}{l}+20.7 \\
+22 \\
+9 \\
+17\end{array}$ & $\begin{array}{r}-9.0 \\
-11.6 \\
-7.5 \\
-7.0\end{array}$ & $\begin{array}{l}-1.0 \\
-1.4 \\
-0.2 \\
-0.5\end{array}$ \\
\hline Centre & Crystal & \multicolumn{5}{|c|}{${ }^{1} \mathrm{~A}_{1}$} & \multicolumn{2}{|c|}{${ }^{3} \mathrm{~B}_{2}$} & \multicolumn{3}{|c|}{${ }^{1} B_{2}$} \\
\hline $\mathrm{PO}_{2}^{-}$ & $\begin{array}{l}\mathrm{KCl} \\
\mathrm{KBr}\end{array}$ & $\begin{array}{l}1094 \\
1081\end{array}$ & $\begin{array}{l}501 \\
494\end{array}$ & $\begin{array}{l}-3 \\
-2\end{array}$ & $\begin{array}{l}-1 \\
-3\end{array}$ & $\begin{array}{l}-0.2 \\
-0.5\end{array}$ & $\begin{array}{l}24929 \\
25031\end{array}$ & $\begin{array}{l}400 \\
-\end{array}$ & 33051 & $\begin{array}{l}840 \\
-\end{array}$ & 363 \\
\hline
\end{tabular}

The results obtained from the study of the luminescence decay of $\mathrm{PO}_{2}^{-}$ centres are given in Table $4^{58}$. At $4.2 \mathrm{~K}$ 'rapid' and 'slow' components $\tau_{1}$ and $\tau_{2}$ exist, whose relationship is essentially dependent upon the excitation frequency. In the case of excitation to higher vibrational levels of state ${ }^{1} B_{2}$ the part of the 'rapid' component increases several times; in the case of excitation to state ${ }^{3} \mathrm{~B}_{2}$ only the 'rapid' component is observed. The two decay components are evidence of the existence of spin sublevels of the ${ }^{3} \mathbf{B}_{2}$ state. The dependence on the excitation frequency shows that (i) singlet-triplet radiationless energy transfer takes place with rates essentially exceeding the vibrational relaxation rates in state ${ }^{1} \mathbf{B}_{2}$, and (ii) the vibrational relaxation in state ${ }^{3} B_{2}$ takes place with conservation of spin.

Table 4. Times of the $\mathrm{PO}_{2}^{-}$centre luminescence decay (in ms)

\begin{tabular}{cccc}
\hline$T(\mathrm{~K})$ & $\mathrm{KCl}$ & $\mathrm{KBr}$ & $\mathrm{KI}$ \\
\hline 300 & 6.0 & 3.0 & 0.67 \\
80 & 6.0 & 3.4 & 1.30 \\
\multirow{2}{*}{$4.2 \tau_{1}$} & 6 & 1.5 & 2 \\
& 120 & 40 & 15 \\
\hline
\end{tabular}

\section{LIBRATIONAL-ROTATIONAL MOTION}

In the case of molecular centres under study the specific feature is the presence of equivalent orientations in the crystal between which transitions 
are possible. The possibility of such transitions means that the molecule in the crystal has quasi-rotational degrees of freedom.

The principal problems of the theory of hindered rotation were discussed by Pauling ${ }^{60}$ on the example of a one-dimensional rotator in the sinusoidal potential field. Some general properties of one-dimensional rotation in potential fields have been discussed ${ }^{61}$. A model of a three-dimensional rotator in a cubic crystal field has been studied ${ }^{62,63}$. A review of hindered rotation (mainly of tunnelling states) of impurity molecules in crystals was given by Narayanamurti and Pohl ${ }^{10}$. The fine rotational structure of infrared absorption bands of intramolecular vibrations of $\mathrm{CN}^{-}, \mathrm{NO}_{2}^{-}$and $\mathrm{NO}_{3}^{-}$centres has been studied ${ }^{34,36}$. The fine rotational structure of zero-phonon lines in the vibronic absorption and luminescence spectra of $\mathrm{NO}_{2}^{-}$was observed ${ }^{13,14}$, and this also enabled data about the rotation (libration) in the excited electronic state to be obtained. The rotational-librational motion was recently displayed also in Raman scattering spectra of molecular centres. Callender and Pershan ${ }^{64}$ interpreted some components of the r.s. line of the vibration of the $\mathrm{CN}^{-}$ion as librational, and assigned the sharp temperature broadening of the vibrational line $v_{3}$ of the $\mathrm{NO}_{2}^{-}$ion to be a result of the rotationallibrational motion. The rotational structure of the $v_{1}$ and $v_{2}$ lines of the $\mathrm{NO}_{2}^{-}$ion has been investigated ${ }^{65}$.

\subsection{Libration and rotation of the $\mathrm{NO}_{2}^{-}$ion}

Thus, the rotational motion of the $\mathrm{NO}_{2}^{-}$ion has been investigated with several spectroscopic methods. Let us discuss briefly the results obtained.

The zero-phonon lines in vibronic spectra, corresponding to the excitation of totally symmetric vibration $v_{2}$ of $\mathrm{NO}_{2}^{-}$, have a similar rotational structure in $\mathrm{KCl}, \mathrm{KBr}$ and $\mathrm{RbCl}$ crystals. In Figure 3 the structure of the $v_{2}$ lines in the absorption and luminescence spectra of the $\mathrm{KCl}$ crystal, the interpretation of transitions and the scheme of lower rotational terms in the ground ${ }^{1} \mathrm{~A}_{1}$ and excited ${ }^{1} \mathrm{~B}_{2}$ electronic states are presented. The rotational terms correspond well to the dependence $\mathrm{F}(K)=A K^{2}$, where $A=2$ and $4 \mathrm{~cm}^{-1}$ are the characteristic frequencies of the one-dimensional rigid rotator model in the ground and excited electronic states, respectively. Electronic-vibrational-rotational (rovibronic) transitions obey the selection rule $\Delta K= \pm 1$.

Polarization measurements of the $\mathrm{KCl}-\mathrm{NO}_{2}^{-}$crystal under uniaxial stress showed $^{35}$ that rotation takes place in a crystal field having four equivalent minima, which corresponds to the orientation of rotation axis a parallel to $\langle 100\rangle$ directions (see Figure 4). The minima correspond to the orientation of the molecular axis in directions $\langle 110\rangle$.

The model of the one-dimensional rotator in field $C_{4 \mathrm{v}}$ also explains the rotational structure of the lines $v_{1}$ and $v_{2}$ in the i.r. spectrum.

However, the interpretation of the fine structure and polarization of r.s. lines requires a somewhat more complicated model.

In Figure 5 the r.s. spectral regions are shown, containing the lines of intramolecular vibrations of $\mathrm{NO}_{2}^{-}$and $\mathrm{NO}_{3}^{-}$ions in $\mathrm{KCl}, \mathrm{KBr}, \mathrm{KI}$ and $\mathrm{RbCl}$ crystals at $10 \mathrm{~K}$. An additional structure of the $v_{3}$ line of the $\mathrm{NO}_{2}^{-}$ion in $\mathrm{KCl}$ and $\mathrm{KBr}$ crystals and of the $v_{1}$ line of the $\mathrm{NO}_{2}^{-}$ion in $\mathrm{KBr}$, and especially in KI crystals was observed. As the tensor of the scattering of the 


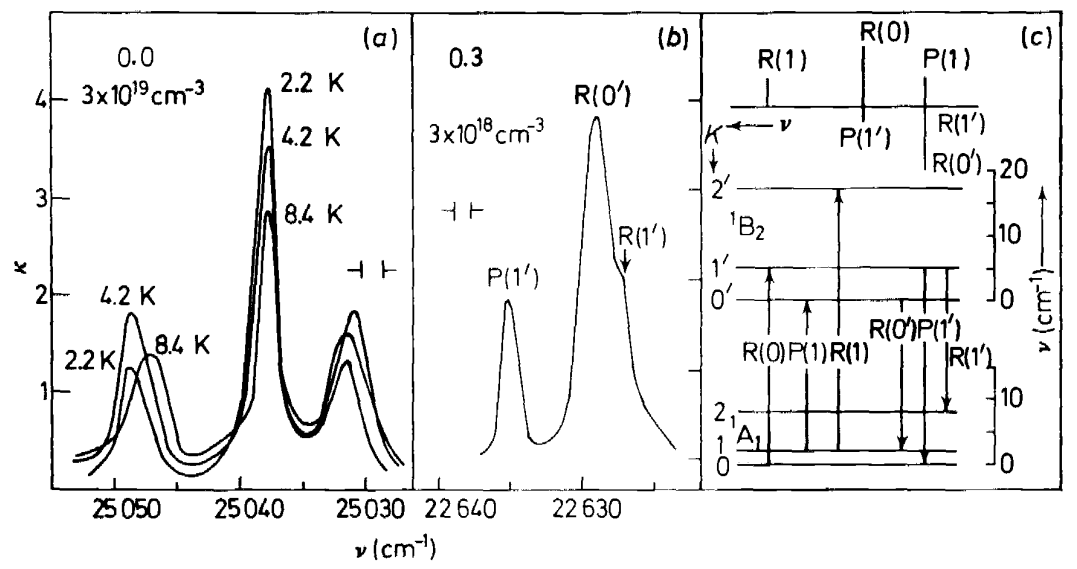

Figure 3. The rotational structure of zero-phonon lines in vibronic spectra of $\mathrm{NO}_{2}^{-}$in $\mathrm{KCl}$.

(a) Pure electronic transition in the absorption spectrum.

(b) Zero-phonon line 0.3 in the luminescence spectrum.

(c) Scheme of rotational terms and interpretation of rovibronic transitions.

antisymmetric vibration $v_{3}$ has no diagonal components, rotation around axis $a$ must lead to the disappearance of the pure vibrational transition in the r.s. spectrum, and to the appearance of vibrational-rotational components with $\Delta K \neq 0$. The broadening of $v_{3}$ lines in $\mathrm{KCl}, \mathrm{KBr}$ and $\mathrm{RbCl}$ crystals with temperature may be interpreted as the result of the thermal population of higher rotational levels. The scheme of vibrational-rotational transitions, given in Figure 5, is obtained on the basis of rotational terms determined from the vibronic spectra applying the selection rule $\Delta K= \pm 2$.

In the $\mathrm{RbCl}$ crystal the $\mathrm{NO}_{2}^{-}$r.s. line $v_{3}$ is much weaker than that in $\mathrm{KCl}$ and $\mathrm{KBr}$. In the $\mathrm{KI}$ crystal the line $v_{3}$ is narrow and no additional structure was found. The polarization measurements of r.s. lines showed that the

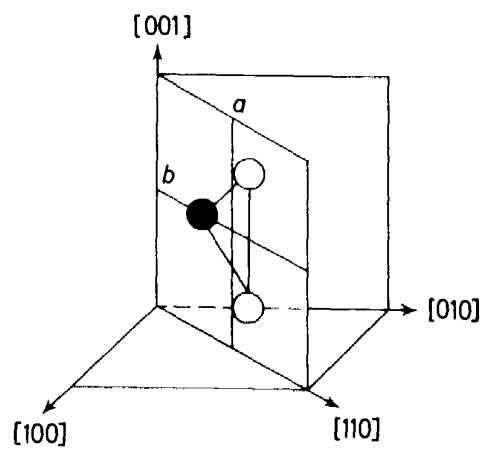

Figure 4. Equilibrium position of the $\mathrm{NO}_{2}^{-}$impurity ion in alkali halide crystals; $a$ and $b$ denote the axes of inertia of the molecule. 
$\mathrm{NO}_{2}^{-}$ions in the $\mathrm{KI}$ crystal have the orientation depicted in Figure 4, and there is no rotation around axis $a$.

At the same time a clear-cut and well-resolved structure is observed in the $v_{1}$ line of $\mathrm{KI}$ (Figure $5 c$ ), which indicates librations around axis $c$. The $\mathrm{NO}_{2}^{-}$ ion in $\mathrm{KCl}, \mathrm{KBr}$ and $\mathrm{RbCl}$ crystals carries out a complicated rotationallibrational motion whose character depends strongly on the host. In $\mathrm{KCl}$

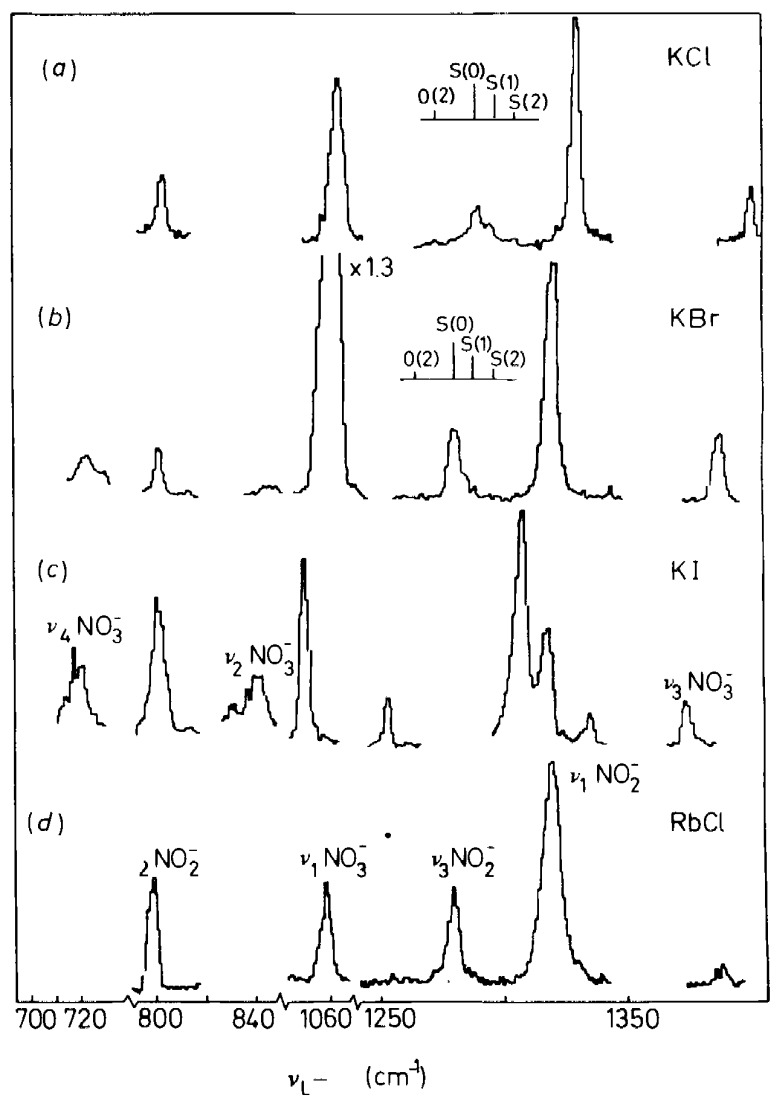

Figure 5. Raman scattering lines of the intramolecular vibrations of ions $\mathrm{NO}_{2}^{-}$and $\mathrm{NO}_{3}^{-}$in alkali halide crystals at $10 \mathrm{~K}$ : excitation with the $4880 \AA$ argon laser line. In $(a)$ and $(b)$ the scheme of the rotational structure is given

and $\mathrm{KBr}$ crystals the reorientation of the molecular axis between equivalent directions $\langle 110\rangle$ takes place mostly by $90^{\circ}$ turns and may be described in the model of a one-dimensional rotator in a weak field $C_{4 v}$. However, the direction of the $a$ axis may be considered as fixed only in the $\mathrm{KCl}$ crystal. In the more 'spacious' $\mathrm{KBr}$ crystal the librations around axis $c$ become possible. In the KI crystal the tunnelling reorientations of the molecular axis by $60^{\circ}$ turns and librations around axis $c$ seem to be the most important. 


\section{K. K. REBANE AND L. A. REBANE}

\subsection{Reorientation of $S_{2}^{-}$in $K I$}

The reorientation of $\mathrm{O}_{2}^{-}$and $\mathrm{S}_{2}^{-}$ions was studied in spin resonance spectra in a well-known series of papers by Känzig ${ }^{25,26,66,67}$. It was determined that $\mathrm{O}_{2}^{-}$in the ground electronic state performs tunnelling transitions between six equivalent equilibrium orientations of the molecular axis along $\langle 110\rangle$. The time of reorientation at helium temperatures was found to be a few seconds. The reorientation of the $\mathrm{S}_{2}^{-}$molecule needs an activation energy, and at $4 \mathrm{~K}$ it is actually frozen in. However, the reorientation takes place under the illumination of the crystal in the $\mathrm{S}_{2}^{-}$absorption band. Treshchalov et $a l^{68}$ have studied the kinetics of such reorientation of $\mathrm{S}_{2}^{-}$in KI by investigations of the luminescence excited by polarized light.

Excitation by polarized light causes depopulation of the orientations in which the molecule absorbs light, and a gradual increase of the number of molecules having other orientations. The time dependence of the intensity of polarized luminescence gives information about the reorientation. From the analysis of curves in Figure 6 it was concluded that the reorientation of

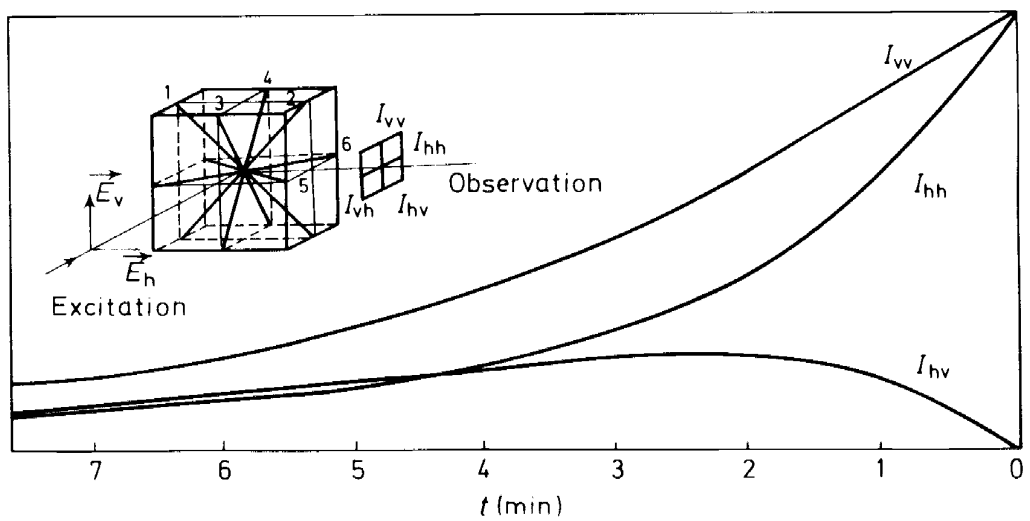

Figure 6. Time dependence of the intensity of polarized luminescence of $\mathrm{S}_{2}^{-}$in $\mathrm{KI}$ due to the reorientation of $S_{2}^{-}$centres under polarized excitation with $\lambda=410 \mathrm{~nm}$ at $4.2 \mathrm{~K}$. The scheme of experiment is given above. Curve $I_{\mathrm{vv}}$ corresponds to the preliminary $20 \mathrm{~min}$ irradiation with $E_{\mathrm{h}}$ polarized light, then the excitation with $E_{\mathrm{v}}$ and the detection of $I_{\mathrm{v}}$. Curves $I_{\mathrm{hh}}$ and $I_{\mathrm{hv}}$ correspond to the preliminary irradiation with $E_{\mathrm{v}}$ and then the excitation with $E_{\mathrm{h}}$ and the detection of $I_{\mathrm{h}}$ and $I_{\mathrm{v}}$

$\mathrm{S}_{2}^{-}$molecules takes place in the course of vibrational relaxation after the emission of a photon, i.e. during the vibrational relaxation in the ground electronic state. Such a situation is probably caused by the existence of two almost overlapping ground state potential curves of the $S_{2}^{-}$molecule (see Section 3.1.). The scheme in Figure 7 describes the possible mechanism of reorientation. The potential curves for the two components of the molecular electronic term ${ }^{2} \Pi_{g}$ are determined from the vibronic series in the luminescence spectrum (see Figure 1a). The energy difference between the minimum points of the curves is $570 \mathrm{~cm}^{-1}$, but the transitions $v \Pi_{\mathrm{g}}^{x} \rightarrow(v+1) \Pi_{\mathrm{g}}^{y}$ ( $v$ is the quantum number of the intramolecular vibration) are nearly reso- 


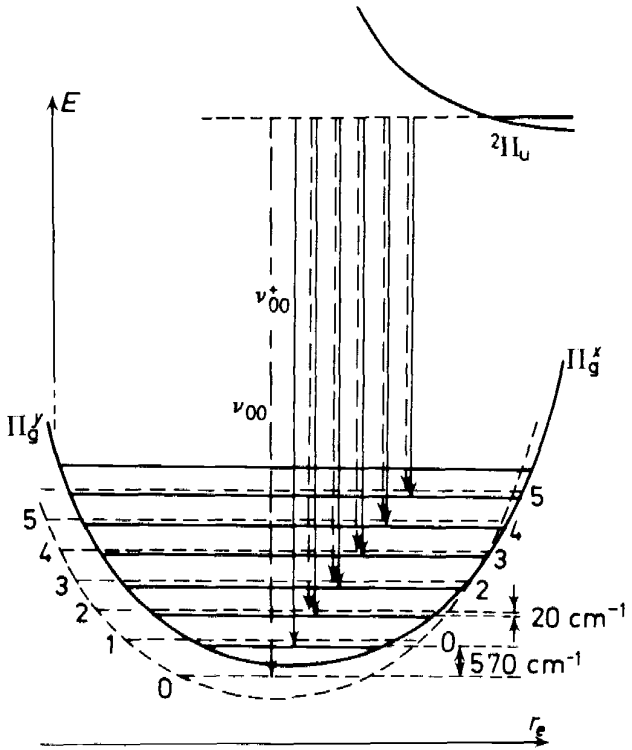

Figure 7. Potential curves of the two components of electronic state ${ }^{2} \Pi_{\mathrm{g}}$ of $\mathrm{S}_{2}^{-}$obtained from the two series of zero-phonon lines in the luminescence of $\mathrm{S}_{2}^{-}$in KI. The emission transitions occur mostly to the $\Pi_{\mathrm{g}}^{x}$ state. The transformation of $\pi$ orbitals from the orientations $x$ to $y$ may be possible if the molecular axis turns by $60^{\circ}$

nant while the energy gap is only $20 \mathrm{~cm}^{-1}$. It was supposed that the vibronic transition is accompanied by the reorientation of the molecular axis.

\section{ELECTRON-PHONON INTERACTIONS}

As was mentioned above, molecular impurity ions in alkali halide crystals represent excellent objects for the experimental study of electron-vibrational and vibrational-vibrational interactions. A number of papers deal with this set of problems ${ }^{24}$.

\subsection{Phonon sidebands in i.r. absorption}

During the last decade phonon sidebands were found and studied in the spectra of $\mathrm{OH}^{-}, \mathrm{NO}_{2}^{-}, \mathrm{NO}_{3}^{-}, \mathrm{NCO}^{-}, \mathrm{NCS}^{-}$and $\mathrm{CN}^{-}$ions ${ }^{69-71}$. Recently Mauring $^{72}$ and $\mathrm{Chi}$ and Nixon ${ }^{73}$ investigated the phonon sideband and its structure in the i.r. absorption spectra of the $\mathrm{SH}^{-}$ion in $\mathrm{KCl}, \mathrm{KBr}$ and $\mathrm{KI}$ crystals (Figure 8 ). In $\mathrm{KBr}$ and $\mathrm{KI}$ crystals low-frequency local vibrations of 95 and $78 \mathrm{~cm}^{-1}$, respectively, occur in the phonon spectrum gap. In KI the gap mode is split into two components by a distance of $1 \mathrm{~cm}^{-1}$. The zerophonon line has in its turn a fine structure which the authors ${ }^{72,73}$ tend to ascribe to various types of aggregate centres. But this conclusion is not in accordance with the studies of the polarization line of the intramolecular vibration of $\mathrm{SH}^{-}$in the r.s. spectrum, which shows that at least 90 per cent 
of all $\mathrm{SH}^{-}$ions in the crystal have the same orientation, parallel to axis $\langle 100\rangle$.

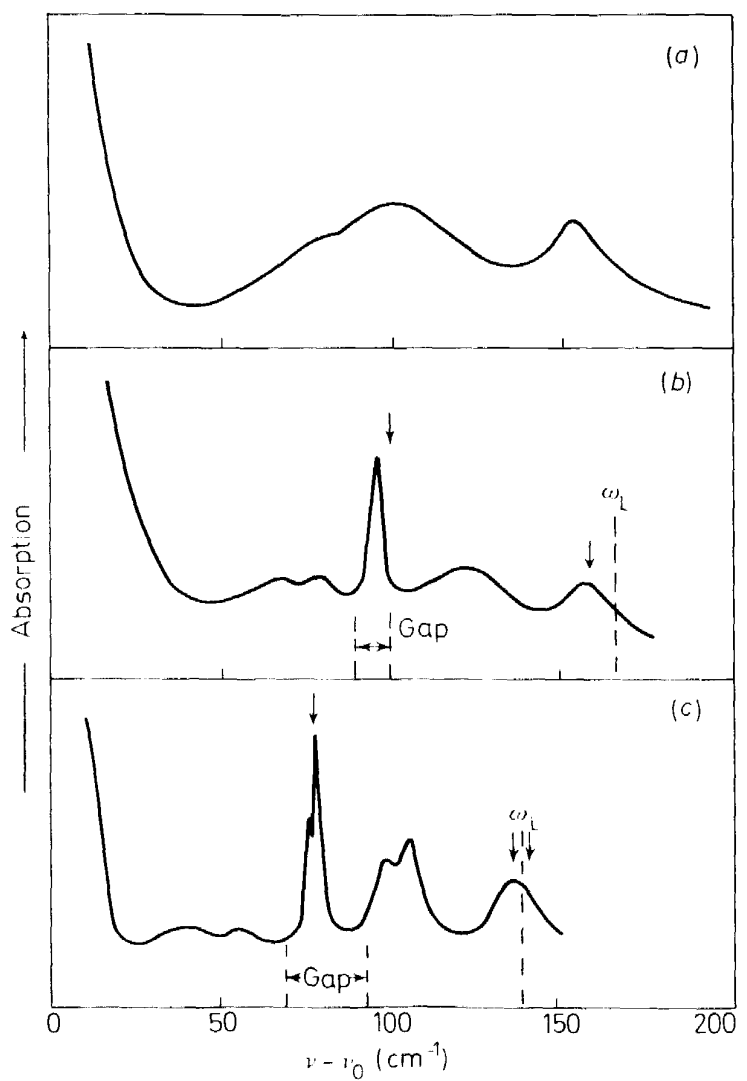

Figure 8 . The phonon sideband accompanying the line of vibrational absorption in the infrared spectrum of the SH ion: (a) $2591 \mathrm{~cm}^{-1}$ in $\mathrm{KCl}$, (b) $2577 \mathrm{~cm}^{-1}$ in $\mathrm{KBr}$ and (c) $2560 \mathrm{~cm}^{-1}$ in KI crystals; temperature is $2 \mathrm{~K}$. Arrows denote the positions of local and pseudolocal vibrations calculated in the approximation of the isotopic defect ${ }^{72}$

\subsection{Structure of phonon sidebands in vibronic luminescence spectra of $\mathrm{O}_{2}^{-}$}

Zero-phonon lines and the fine structure of phonon sidebands in the luminescence spectra of $\mathrm{O}_{2}^{-}$centres in alkali halides were found and interpreted in $1965^{74}$ in accordance with the theoretical picture of the 'ideal' case $^{21}$. The detailed analysis of phonon wings has been carried out ${ }^{17-19,24,75}$.

The $\mathrm{O}_{2}^{-}$ion carries only small perturbations in the local dynamics of the crystal. Therefore the fine structure of phonon sidebands offers valuable information about the phonon spectrum of the host crystal.

\subsection{Anharmonicity effects}

In the centres under study a number of effects of anharmonic interaction between vibrations is also revealed. Let us briefly consider some of them. 
In the luminescence spectrum of $\mathrm{O}_{2}^{-}$the 'anomalous' dependence of the widths of vibronic sub-bands, intensities and widths of zero-phonon lines, and also the Stokes losses on crystal vibrations on the quantum numbers of vibronic sub-bands is clearly observed. (In $\mathrm{S}_{2}^{-}$in a less distinct way.) The behaviour of these characteristics seems to correspond to the decrease of the anharmonic coupling between local and crystal vibrations with the increase of quantum number of the local vibration level ${ }^{76-78}$.

Let us also note that in the $\mathrm{NO}_{2}^{-}$ion the anharmonicity of lower excited levels of vibration $v_{2}$ is practially absent and the anharmonicity of vibration $v_{1}$ is negative. This is studied in an especially exact way on the example of $\mathrm{NO}_{2}^{-}$in $\mathrm{KCl}$ (see Table 3 and Ref. 13).

\subsection{Zero-phonon lines}

The study of zero-phonon lines and their temperature behaviour gives information about the mechanism of phonon coupling, the splitting of electronic levels and the librational-rotational motion.

The results obtained in the study of zero-phonon lines in the luminescence spectra of $\mathrm{O}_{2}^{-}$in $\mathrm{KCl}, \mathrm{KBr}$ and $\mathrm{KI}$ crystals, and $\mathrm{S}_{2}^{-}$in $\mathrm{KI}$, refer to an important role of librational vibrations in the mechanism of temperature broadening of zero-phonon lines ${ }^{79}$.

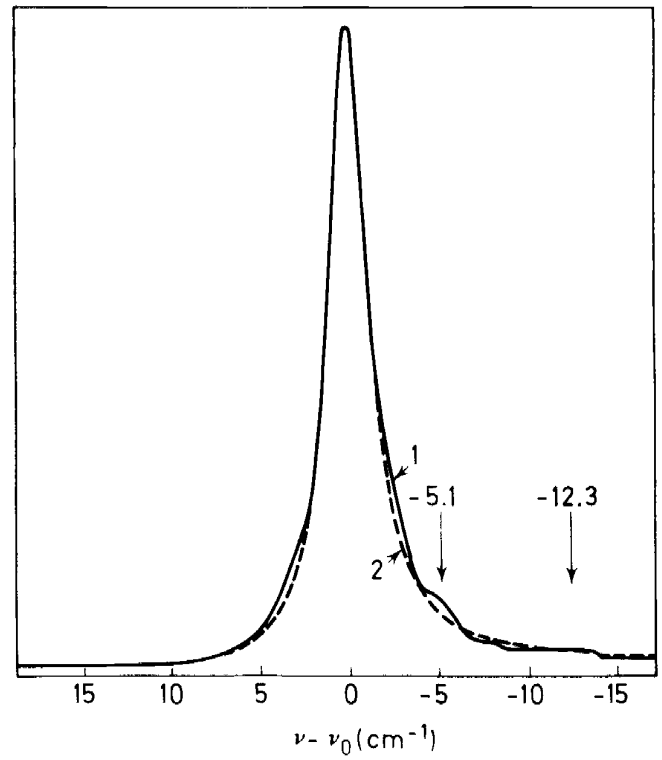

Figure 9. The shape of the zero-phonon line number 7 in the luminescence spectrum of $\mathrm{O}_{2}^{-}$ in $\mathrm{KCl}$ at $4.2 \mathrm{~K}$ (solid line). The dashed line is the approximating asymmetric Lorenz curve

The analysis of the shape and its temperature dependence was carried out in the case of the zero-phonon line number $v=7$ in the $\mathrm{O}_{2}^{-}$spectrum in $\mathrm{KCl}$ at temperatures of $4.2-40 \mathrm{~K}$ (Figure 9). The real line shape (obtained after 


\section{K. K. REBANE AND L. A. REBANE}

the corrections to the apparatus function were made) shows weak components at -5 and $-12 \mathrm{~cm}^{-1}$ from the main line (Figure 9); these are most probably brought about by the librational vibrations. The shape of the main line is well approximated with the Lorentz curve with asymmetry on the long-wave side. As the temperature increases, the components overlap and the contour becomes smoother.

The temperature dependence of half-widths $\delta$ of zero-phonon lines is demonstrated in Figure 10. It should be noted that the increase of widths

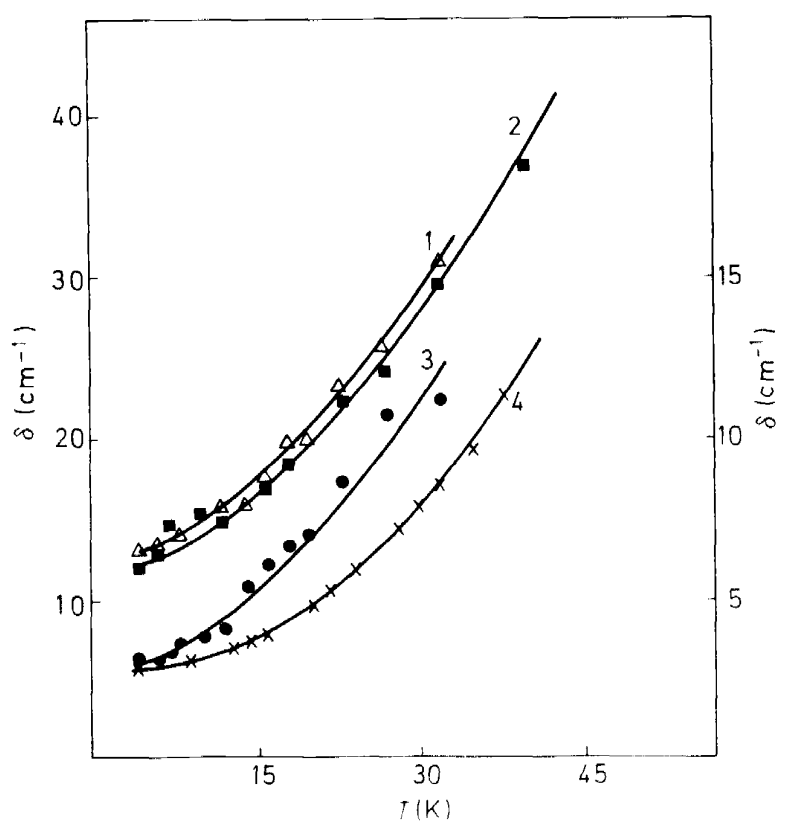

Figure 10. Plot of half-widths of zero-phonon lines in the luminescence spectra of $\mathrm{O}_{2}^{--}$centres versus temperature. Experimental values are represented by discrete points; solid lines are power function $\delta(T)=\delta(0)+a T^{n}$ approximating the experimental data. 1.2 and 3 show half-widths of lines numbers 4.6 and 9. respectively. in the spectrum of $\mathrm{O}_{2}^{-}$in $\mathrm{K} \mathrm{Br}$ (the left scale):

4 shows the half-width of line number 7 in the spectrum $\mathrm{O}_{2}^{-}$in $\mathrm{KCl}$ (the right scale)

with temperature begins immediately at helium temperatures---a region of constant width is absent. Secondly, the dependence $\delta(T)$ is nearly quadratic in $T$.

The dependence, close to a quadratic one, observed in the cases of $\mathrm{O}_{2}^{-}$and $\mathrm{S}_{2}^{-}$in the interval of temperatures 4-50 K, gives evidence about the existence of some additional low-frequency pseudolocal states in these molecular centres whose thermal population involves considerable changes at the mentioned temperatures. It seems to be reasonable to consider that the pseudolocal vibrations of librational type, the existence of which in the molecular centres under study is beyond doubt because of their clear appear- 
ance in luminescence spectra ${ }^{18,19}$, are the low-frequency vibrations which cause the $T^{2}$ law of broadening already at rather low temperatures.

\section{HOT LUMINESCENCE}

Hot luminescence (h.l.) may be roughly interpreted as the radiation emitted during vibrational relaxation before the establishment of thermal equilibrium between vibrational levels. It is evident that in the case of the luminescence centres in which vibrational relaxation takes place very rapidly, and to which the molecular ions under study belong, h.l. is very weak. If ordinary luminescence is not quenched h.l. is as many times weaker than ordinary luminescence as the vibrational relaxation time is shorter than the optical lifetime. In rapidly relaxing luminescence centres the intensity of $h . l$. is about the same as that of Raman scattering by impurities in a crystal.

H.1. in rapidly relaxing impurity centres has been experimentally and theoretically studied in about ten publications $\mathrm{s}^{80-86}$. The conception of h.l. has been applied for exciton states of crystals ${ }^{87}$.

\subsection{Vibronic hot luminescence of $\mathrm{NO}_{2}^{-}$centres}

The $\mathrm{NO}_{2}^{-}$molecular ion in alkali halides is a very suitable object for the study of h.l. in rapidly relaxing systems for several reasons: a well-defined vibronic and rovibronic structure in the absorption spectra as well as in the luminescence spectra, a small quantum yield of ordinary luminescence ${ }^{88,89}$ and also other characteristics favourable from a theoretical viewpoint ${ }^{83,84}$.

H.l. of $\mathrm{NO}_{2}^{-}$was studied in a number of alkali halide hosts ${ }^{80,81,88}$. Not only h.l. spectra but also the dependence of these spectra on the excitation frequency and the excitation spectra of single h.l. lines were also studied. The phonon sidebands and the rotational structure of h.l. lines were detected ${ }^{20,89}$. The rotational structure of vibronic lines studied in the case of $\mathrm{KCl}-\mathrm{NO}_{2}^{-}$was found to be, in its general features, analogous to that in ordinary luminescence spectra but there were also remarkable differences in the distribution of intensities between the rotational components arising from the hot nature of the transitions.

Experimental data about vibronic h.l. are in good agreement with the general ideas about the rapid relaxation of the energy of excited local vibrations in comparison with the optical lifetime. The absence of observable peculiarities in the shape of h.l. phonon sidebands gives evidence about the rapid decay of the crystal phonon packet in comparison with the lifetime of the excited states of local vibrations.

The data about the distribution of intensities in h.l. were supplemented with some other experimental data ${ }^{88,89}$ and the vibrational relaxation rates, radiationless transition rates and full lifetimes of four lowest vibrational levels of local vibrations in the excited electronic state were determined ${ }^{90,91}$. The time of decay of the first excited level of the local vibration of $\mathrm{NO}_{2}^{-}$in $\mathrm{KCl}$ into phonons of crystal vibrations was, for example, $1.3 \times 10^{-11} \mathrm{~s}$, or about 230 periods of that vibration.

\subsection{Rovibronic hot luminescence of $\mathrm{NO}_{2}^{-}$}

As was mentioned above, the specific feature of $\mathrm{NO}_{2}^{-}$is the quasi-free 
(one-dimensional) rotation in alkali halide crystals. Already in the first experiments on a fine rovibronic structure it was found that in cooling the crystal from 4.2 to $2 \mathrm{~K}$ there is no change in the distribution of intensities between the components of rotational structure: this should have taken place if it had been possible to establish thermal equilibrium over rotational states of the $\mathrm{NO}_{2}^{-}$molecule during the lifetime of the excited electronic state $^{13}$

In order to determine the rotational relaxation times the dependence of the distribution of intensities in rotational structure of luminescence spectra of $\mathrm{NO}_{2}^{-}$in $\mathrm{KCl}$ on the selective excitation of rotational sublevels was studied ${ }^{92}$. The results confirmed the slowness of rotational relaxation and also allowed the determination of the corresponding time, which was $3 \times 10^{-8} \mathrm{~s}$ or about 5000 periods of rotation in the case of the transition $K^{\prime}=1 \rightarrow K=0$ ( $K$ - the quantum numbers of the states of the one-dimensional rotator). This exceeds by 2.4 times the lifetime of the excited electronic state (determined mainly by radiationless transitions ${ }^{88}$ ). Thus. the lowest excited rotational states (excited electronic state, ground state of local modes) of $\mathrm{NO}_{2}^{-}$in $\mathrm{KCl}$ relax rather slowly. The reasons for such a non-trivial situation (a dipole molecule rotating in an ionic crystal hardly transfers energy into the crystal) have been discussed ${ }^{93-95}$. Higher rotational levels of that vibronic state, in accordance with the theory ${ }^{93}$, decay much more rapidly, the relaxation times being about $10^{-11} \mathrm{~s}$, i.e. of the same order of magnitude as those of the local modes of vibrations ${ }^{94}$.

\subsection{Infrared hot luminescence of $\mathrm{OH}^{-}$centres in alkali halides}

In recent papers ${ }^{96-98}$ attempts have been made to indicate hot luminescence of one more kind-infrared radiation from the excited vibrational levels in the ground electronic state. These transitions, unlike infrared absorptions, have an extremely low intensity which is caused by very long optical lifetimes and rather high relaxation rates of the vibrational states of the molecular ion in the crystal. The $\mathrm{OH}^{-}$molecular ion in alkali halides $(\mathrm{KCl}$ and $\mathrm{KBr}$ ) has been found to be a suitable system for these investigations. It seems that the first evidence demonstrating the possibility of an experimental study of such a type of h.l. has really been obtained.

\section{CONCLUSION}

The crystals activated with simple negative molecular ions are prospective objects of the joint investigations of molecular spectroscopy and solid state physics. In future investigations it would be useful to consider the molecular ions as probes for studying electron-hole and ionic processes in host crystals, pre-ionization and also the interesting phenomena connected with the preionization states and the decay of excited electronic states with the departure of an electron or with the chemical transformations of a negative molecular ion in the ionic matrix crystal.

\section{ACKNOWLEDGEMENTS}

The authors are grateful to R. A. Avarmaa, P. M. Saari and T. H. Mauring 
for collaboration in the study of the problems of this review, and also to D. B. Fitchen, J. Rolfe and T. Timusk for discussion and for the reprints and preprints of their papers.

\section{REFERENCES}

1 W. Känzig, H. R. Hart. Jr. and S. Roberts. Phys. Rev. Letters, 13, 543 (1964).

2 U. Kuhn and F. Lüty, Solid State Commun., 3, 31 (1965).

${ }^{3}$ I. W. Shepherd and G. Feher. Phys. Rev. Letters, 15, 194 (1965).

${ }^{4}$ W. N. Lawless, J. Phys. Chem. Solids, 30, 1161 (1969).

${ }^{5}$ V. Korrovits and G. Liidja. Eesti NSV Teaduste. Akad. Toimetised. Fü̈̈sikalis-Mat.. 20. 156 (1971).

6 V. Korrovits, G. Liidja and V. Mihkelsoo, Prib. Tehn. Eksperim., 3, 273 (1973).

${ }^{7}$ K. Knop and W. Känzig. Phys. Kondens. Materie, 15. 201 (1972); Solid State Commun., 11. 791 (1972)

${ }^{8}$ M. V. Klein, B. M. Wedding and C. H. Chan, Bull. Amer. Phys. Soc., 12. 78 (1967).

9 L. Ralph, Chenk-Kin Chan and M. V. Klein, Phys. Rev., 186, 852 (1969).

10 V. Narayanamurti and R. O. Pohl, Rev. Mod. Phys., 42. 210 (1970).

11 L. A. Rebane, Eesti NSV Teaduste Akad. Toimetised. Fü̈sikalis-Mat., Akad. Nauk Est. SSR. 37. 14 (1968).

12 K. Rebane. L. Rebane and O. Sild, Internat. Conf. Luminescence, Budapest, 2, C5. 115 (1966).

13 R. Avarmaa and L. Rebane, Phys. Status Solidi, 35, 107 (1969).

14 A. R. Evans and D. B. Fitchen, Phys. Rev.. B2. 1074 (1970).

15 J. Rolfe, J. Chem. Phys., 40, 1664 (1964) : 49, 4193 (1968).

16 K. K. Rebane, A. I. Laisaar, L. A. Rebane and O. I. Sild, Izv. Akad. Nauk SSSR. Ser. Fiz.. 31. 2010 (1967).

17 K. Rebane, L. Rebane and O. Sild, Localized Excitation in Solids. p. 117. Plenum Press. New York (1968).

18 L. A. Rebane and P. M. Saari, Fiz. Tverd. Tela, 13, 756 (1970).

19 L. A. Rebane, Opt. i Spektroskopiya, 31, 6320 (1971).

${ }^{20}$ K. K. Rebane, Spektroskopija kristallov. Proceedings of III Symposium on Spectroscopy of Crystals, p. 42. Leningrad, 4 8 May 1970, Nauka, Leningrad (1973) (in Russian).

${ }^{21}$ K. K. Rebane. Impurity Spectra of Solids, Plenum Press. New York-London (1970).

22 E. Hutchinson and P. Pringsheim, J. Chem. Phys., 23, 1113 (1955).

23 T. Timusk and W. Staude, Phys. Rev. Letters, 13, 373 (1964).

24 L. A. Rebane, Physics of Impurity Centres in Crystals, p. 353, (ed. G. S. Zavt). Tallinn (1972).

25 W. Känzig, J. Phys. Chem. Solids, 23, 479 (1962).

${ }^{26}$ K. Bachmann, W. Känzig. H. R. Zeller and A. Zimmermann. Phys. Kondens. Materie. 7, 360 (1968).

27 M. Ikezawa and J. Rolfe. J. Chem. Phys., 58. 2024 (197.3).

${ }^{28}$ L. Rebane. Eesti NSV Teaduste Akad. Toimetised. Füüsikalis-Mat., 17, 72 (1968).

29 J. Muggli and H. U. Bayeler, Solid State Commun., 8, 217 (1970).

30 H. U. Bayeler. R. Baumann and W. Känzig, Phys. Kondens. Materie. 11. 286 (1970).

31 U. Kuhn and F. Lüty, Solid State Commun., 2. 281 (1964).

32 H. Paus and F. Lüty, Phys. Status Solidi, 12, 341 (1965).

${ }^{33}$ H. Hörtel and F. Lüty, Phys. Status Solidi, 12, 347 (1965).

${ }^{34}$ W. D. Seward and V. Narayanamurti, Phys. Ret., 148, 463 (1966).

35 R. A. Avarmaa Opt. i Spektroskopiya, 32, 959 (1972).

36 V. Narayanamurti, W. D. Seward and R. O. Pohl. Phys. Rer., 148, 481 (1966).

37 T. Mauring, Eesti NSV Teaduste Toimetised. Fü̈isickalis-Mat.. 17, 232 (1968); 18. 105 (1969); 20, 232 (1971).

38 V. N. Gnatovskaya and I. N. Halimonova, Fiz. Tverd. Tela, 9, 2590 (1967).

39 V. N. Gnatovskaya, B. K. Krulikovskii and I. N. Halimonova, Ukr. Fiz. Zh., 17. 1461 (1972).

40 J. C. Decius, Spectrochim. Acta, 21, 15 (1965).

41 T. I. Maksimova Phys. Status Solidi, 33, 547 (1969).

42 M. P. Lisitsa and L. I. Berezhinskii, Ukr. Fiz. Zh., 15, 1347 (1971)

43 L. I. Berezhinskii, B. K. Krulikovskii and V. F. Beresa, Ukr. Fiz. Zh., 15, 261 (1971).

44 L. M. Branscomb, Adv. Electron. Electron Phys., 9, 61 (1957). 
45 R. K. Cirran. J. Chem. Phys., 35, 1849 (1961).

46 M. J. W. Boness and G. I. Schulz, Phys. Rev., A2, 2182 (1970)

47 R. J. Celotta R. A. Bennett, J. L. Hall, M. W. Siegel and J. Levine, Phys. Rev.. A6. 631 (1972).

48 R. R. Smardzewski and L. Andrews. J. Chem. Phys., 57. 1327 (1972).

${ }^{49}$ L. Rebane and P. Saari. Eesti NSV Teaduste Akad. Toimetised. Füüsikalis-Mat.. 19. 123 (1970).

so R. A. Avarmaa. Tr. Inst. Fiz. Astron., Akad. Nauk Est. SSR, 37, 52 (1968).

51 1. Sildos and L. Rebane, Eesti NSV Teaduste Akad. Toimetised. Fü̈̈sikalis Mat.. 20. 354 (1971)

52 D. Spence and G. J. Schulz, Phys. Rev.. A2. 1809 (1970).

53 M. Krauss and D. Neimann, Phys. Rev., A7, 6 (1973).

54 J. R. Morton. J. Chem. Phys., 43, 3418 (1965).

55 L. F. Vannotti and J. R. Morton. Phys. Rer.. 161. 161 (1967).

5t R. A Avarmaa Eesti NSV Te'aduste Akad. Toimetised. Hü̈sikalis- Mat.. 17. 78 (1968).

57 B. T. Platsenov, V. P. Avdokin. V. Kapishovskii and G. A. Mikhaltsenko. Izl. Akad. Nauk SSSR, Ser. Fiz., 31, 2025 (1967).

58 R. A. Avarmaa, Izv. Akad. Nauk SSSR, Ser. Fiz., 36, 1066 (1972).

59 H. J. Maria D. T. Armstrong and S. P. McGlynn. J. Chem. Phys., 48. 4694 (1968).

${ }^{60}$ L. Pauling. Phys. Rev.. 36. 430 (1930).

${ }^{61}$ K. Rebane and O. Sild. Eesti NSV Teaduste Akad. Toimetised. Fü̈sikalis-Mat.. 19. 311 (1970).

62 A. I. Devonshire. Proc. Roy. Soc.. A153 601 (1936).

${ }^{63}$ P. Sauer, Z. Phys. 199. 280 (1967).

64 R. Callender and P. S. Pershan, Phys. Rev. Letters, 23, 947 (1969).

${ }_{65}$ K. K. Rebane, L. A. Rebane. T. J. Haldre and A. A. Gorokhovskii Advances in Raman Spectroscopy, Vol. 1. p. 379. Heyden and Son Ltd, London (1973).

66 H. R. Zeller and W. Känzig, Helv. Phys. Acta, 38, 638 (1965).

67 H. R. Zeller, R. T. Shuey and W. Känzig. J. Phys. (Paris). Colloq.. 28. 81 (1967)

68 A. Treshchalov. I. Sildos and L. Rebane. Eesti NSV Teaduste Akad. Toimetised. Fü̈usikalisMat. 451 (1973).

69 R. Bonn. R. Metselaar and J. Van der Elsken, J. Chem. Phys.. 46. 1988 (1967).

${ }^{70}$ G. R. Field and W. F. Sherman. J. Chem. Phys. 47, 2378 (1967).

71 A. I. Stechanov and T. I. Maksimova, Fiz. Tverd. Tela, 9, 2590(1967); Izr. Akad. Nauk SSSR. Ser. Fiz., 31, 2017 (1967).

72 T. H. Mauring. Thesis, Tartu (1973),

73 C.-K. Chi and E. R. Nixon. J. Phys. Chem. Solids, 33, 2101 (1972).

${ }^{74}$ K. Rebane and L. Rebane. Eesti NSV Teaduste Akad. Toimetised. Fü̈̈sikalis-Mat.. 14. 309 (1965).

75 J. Rolfe, M. Ikezawa and T. Timusk, Phys. Rev., B7. 3913 (1973).

76 L. A. Rebane, O. I. Sild and T. J. Haldre, Izv. Akad. Nauk SSSR, Ser. Fiz.. 35. 1395 (1971).

77 K. K. Rebane and O. I. Sild, Opt. i Spektroskopiya, 23, 414 (1967).

78 L. A. Rebane and Y. I. Kharchenko, Opt. i Spektroskopiya, 28, 943 (1970).

79 A. M. Freiberg and L. A. Rebane, XI European Congress on Molecular Spectroscopy. Abstract No. 110, Tallinn (1973).

${ }^{80}$ K. Rebane and P. Saari, Eesti NSV Teaduste Akad. Toimetised, Füüsikalis-Mat.. 17. 241 (1968).

81 P. Saari and K. Rebane. Solid State Commun., 7, 887 (1969); P. Saari and K. Rebane. Eesti NSV Teaduste Akad. Toimetised, Fü̈̈sikalis-Mat., 18, 225 (1969).

\$2 T. B. Tamm, Opt. i Spektroskopiya, 32, 623 (1972).

${ }^{83}$ K. K. Rebane, Vtorichnoe svechenie primesnogo tsentra kristalla, Akademia Nauk Est SSSR. Tartu (1970).

84 V. V. Hizhnyakov, K. K. Rebane and I. J. Tehver, Light Scattering Spectra of Solids p. 513, (ed. G. B. Wright), Springer-Verlag, New York (1968).

85 E. D. Trifonov and K. Poiker, Fiz. Tverd. Tela, 10, 1705 (1968).

86 D. L. Dexter, Phys. Status Solidi, 51, 354 (1972).

87 E. Gross, S. Permogorov, V. Travnikov and A. Selkin, J. Phys. Chem. Solids. 32. 2595 (1971); M. Klein and P. J. Colwell, Light Scattering in Solids, p. 65, (ed. M. Balkanski), Flammarion Sciences, Paris (1971).

${ }^{88}$ K. K. Rebane, R. A. Avarmaa and L. A. Rebane, Izv. Akad. Nauk SSSR, Ser. Fiz.. 32, 1381 (1968) ; L. Rebane, P. Saari and R. Avarmaa, Eesti NSV Teaduste Akad. Toime' ised. FüüsyalisMat., 19, 44 (1970). 
SMALL MOLECULAR IONS AS IMPURITY CENTRES IN CRYSTALS

89 K. K. Rebane, R. A. Avarmaa. I., A. Rebane and P. M. Saari, Light Scattering in Solids, p. 72, (ed. M. Balkanski), Flammarion Sciences, Paris (1971).

90 P. Saari, Phys. Status Solidi, (b), 47, K79 (1971).

91 P. M. Saari, XI European Congress on Molecular Spectroscopy, Abstract No. 104, Tallinn (1973).

92 R. Avarmaa and P. Saari, Phys. Status Solidi, 36, K177 (1969).

${ }^{93}$ O. Sild, Physics of Impurity Centres in Crystals, p. 383, (ed. G. S. Zavt). Tallinn (1972).

94 P. Saari, Thesis, Tartu (1972).

95 R. Avarmaa, Thesis, Tartu (1970).

96 K. K. Rebane, P. M. Saari and T. H. Mauring, Izv. Akad. Nauk SSSR, Ser. Fiz., 37, 848 (1973).

97 K. Rebane, T. Mauring and R. Vanem, Eesti NSV Teaduste Akad. Toimeíised FüüsikalisMat., 21, 215 (1972).

98 R. Capelletti, F. Fermi and R. Fieschi, Colour Cenires in lonic Crystals, Abstract No. 108, University of Reading, UK (1971). 